\title{
Comparative Study of Depression and Family Environment among Male and Female Adults
}

\author{
Seema Bajaj and Harkawal Jeet Singh
}

\begin{abstract}
Aim: To compare Depression and family Environment among male and female adults. Method: A sample of 200 adults (100 males and 100 females) was selected from Ludhiana District. For data collection, Beck Depression Inventory-II by Aaron T. Beck, Robert A.Steer and Gregory K. Brownand Family Environment Scale by Dr. Harpreet Bhatiaand Dr. N.K. Chadha were used. Family Environment scale measures three dimensions - Conflict, acceptance and caring and Independence. Results: The results revealed that a significant negative relationship was found between Depression and Conflict, Acceptance \& Caring and Independence dimensions of family environment among male and female adults. Conclusion: Depression among adults is significantly correlated with all the three dimensions of family environment irrespective of their gender.
\end{abstract}

\author{
Seema Bajaj \\ Assistant Professor \\ Master Tara Singh Memorial College for Women \\ Ludhiana (Punjab) India \\ E-mail: seemabajaj74in@yahoo.co.in \\ Harkawal Jeet Singh \\ Consultant \\ Homoeopathic Clinic, \\ Ludhiana (Punjab) India
}

Key Words: Depression, Environment, Family. Adults

DOI: $10.18376 /$ jesp/2018/v14/i1/111292

\section{Introduction}

Depression is more than just the sad mood. It is a serious condition which affects our physical as well as mental health. People who are severely depressed believe that they are helpless. Depression can occur at any age group. The symptoms of depression are pains affecting other body areas like head, back, neck or chest, lethargy, disturbances of appetite and sleep which could easily be passed on as indicating a physical illness. Seligman, (1990) referred to depression as the "ultimate pessimism." In India, the family is the most important organization that has survived through the ages. The family environment is affected by a number of factors like the family size, moral religious emphasis, culture and values, family dynamics, control and independence in the family, nature of family, number of the children in family, marital relationships between wife and husband, maternal employment, and socio economic and religious background of the family. Cairney, J. et al. (2003) examined the effect of the stress and social support on the relationship between singleparent status and the depression. Single and married mothers who participated in the survey had been derived from the general sample. Analyses showed that, the single mothers were more likely to have suffered the episode of depression as compared with the married mothers,(12-month prevalence), to report a higher levels of chronic stress, a greater number of childhood adversities and the more recent life events. The Single mothers reported lower levels of the social involvement, the perceived social support and the frequency of contact with family and friends than the married mothers. Taylor, Shelly E. et. al. (2006) conducted the Study on the Early Family Environment, Current Adversity, the Serotonin Transporter Promoter Polymorphism, and Depressive symptomatology and found that a non clinical sample of 118 young adult men and women 
completed the assessments of the early family environment, psychosocial resources, recent stressful events and the psychological distress, including depressive symptomatology. It was found that the stressful early family environment was significantly related to depressive symptomatology. Akram \& Khuwaja (2014) conducted a study on depression among working and nonworking women. It was observed that the working women who lived in nuclear family system reported higher level of depression than those for joint family systems. The result showed that non working women have more depression tendencies as compared to their working women counterparts. However factors like family system, education, monthly income, number of children, and age appeared to be associated with depression of the participants. Further the results indicated that women working as managers and lawyers were more depressed than teachers, lecturers self-employed and doctors.

\section{Material and Method}

The present study was conducted on 200 adults (100 males and 100 females) from Ludhiana district. For data collection, Beck Depression Inventory-II by Aaron T. Beck, Robert A. Steer, and Gregory K. Brown and Family Environment Scale by Dr. Harpreet Bhatia and Dr. N.K. Chadha were used.

\section{Results and Discussion}

Table 1. Correlation between Depression and Family Environment of Male Adults

\begin{tabular}{lcc}
\hline Variables & N & r \\
\hline Depression and Conflict & 100 & $-\mathbf{0 . 7 9}$ \\
Depression and Acceptance \& Caring & 100 & $-\mathbf{0 . 7 7 ^ { * * }}$ \\
Depression and Independence & 100 & $-\mathbf{0 . 7 9}$ \\
\hline \multicolumn{2}{c}{$*$ Significant at .01 level } &
\end{tabular}

Table 1 show the coefficient of correlation between depression and conflict dimension of family environment of male adults as -0.79 which is negative and significant at .01 level of confidence which shows that there exists a significant negative relationship between depression and conflict dimension of family environment of male adults. As the scale indicates higher the score lower the conflict, the results indicate that the male adults having higher level conflict in the family experience more depression and the male adults having low level conflict in the family experience less depression. The coefficient of correlation between depression and Acceptance \& Caring dimension of family environment of male adults as -0.77 which is negative and significant at .01 level of confidence which shows that there exists a significant negative relationship between depression and Acceptance \& Caring dimension of family environment of male adults. As the scale indicates higher the score higher the Acceptance \& Caring, the results indicate that the male adults having lower level Acceptance \& Caring in the family experience more depression and the male adults having high level conflict in the family experience less depression. The coefficient of correlation between depression and independence dimension of family environment of male adults as -0.79 which is negative and significant at .01 level of confidence which shows that there exists a significant negative relationship between depression and independence dimension of family environment of male adults. As the scale indicates higher the score lower the independence, the results indicate that the male adults having lower level independence in the family experience more depression and the male adults having high level independence in the family experience less depression. 


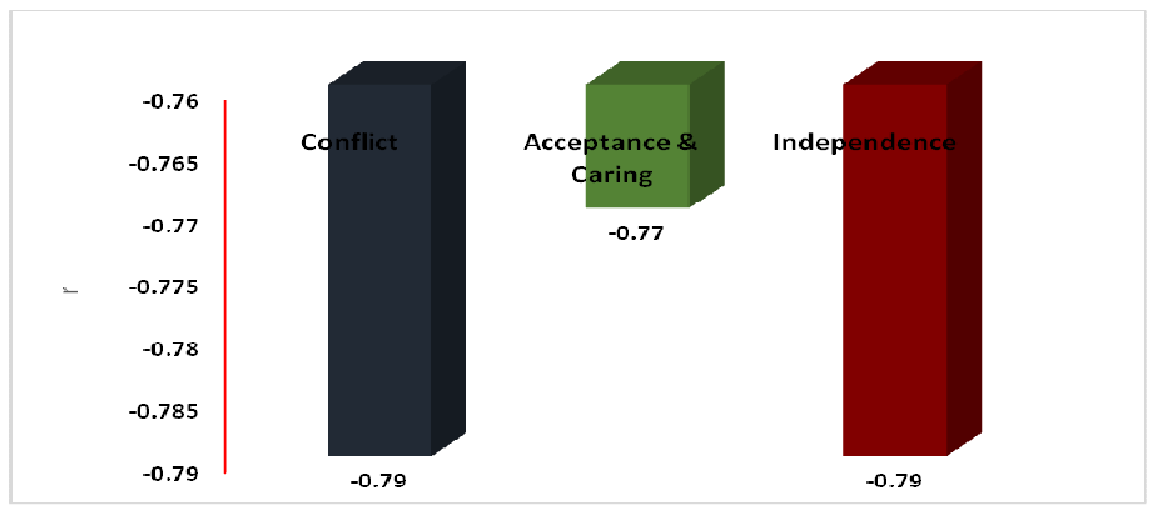

Figure 1. Correlation between Depression and Family environment of Male adults

Table 2. Correlation between Depression and Family Environment of Female adults

\begin{tabular}{lll}
\hline Variables & $\mathbf{N}$ & $\mathbf{r}$ \\
\hline Depression and Conflict & $\mathbf{1 0 0}$ & $\mathbf{- 0 . 8 4 ^ { * * }}$ \\
Depression and Acceptance \& Caring & $\mathbf{1 0 0}$ & $\mathbf{- 0 . 8 1 ^ { * * }}$ \\
Depression and Independence & $\mathbf{1 0 0}$ & $\mathbf{- 0 . 8 0}$ \\
\hline \multicolumn{2}{c}{ ** Significant at .01 level }
\end{tabular}

Table 2 show the coefficient of correlation between depression and conflict dimension of family environment of female adults as -0.84 which is negative and significant at .01 level of confidence which shows that there exists a significant negative relationship between depression and conflict dimension of family environment of female adults. As the scale indicates higher the score lower the conflict, the results indicate that the female adults having higher level conflict in the family experience more depression and the female adults having low level conflict in the family experience less depression. The coefficient of correlation between depression and Acceptance \& Caring dimension of family environment of female adults as -0.81 which is negative and significant at .01 level of confidence which shows that there exists a significant negative relationship between depression and Acceptance \& Caring dimension of family environment of female adults. As the scale indicates higher the score higher the Acceptance \& Caring, the results indicate that the female adults having lower level Acceptance \& Caring in the family experience more depression and the female adults having high level conflict in the family experience less depression. The coefficient of correlation between depression and independence dimension of family environment of female adults as -0.80 which is negative and significant at .01 level of confidence which shows that there exists a significant negative relationship between depression and independence dimension of family environment of female adults. As the scale indicates higher the score lower the independence, the results indicate that the female adults having lower level independence in the family experience more depression and the female adults having high level independence in the family experience less depression. 


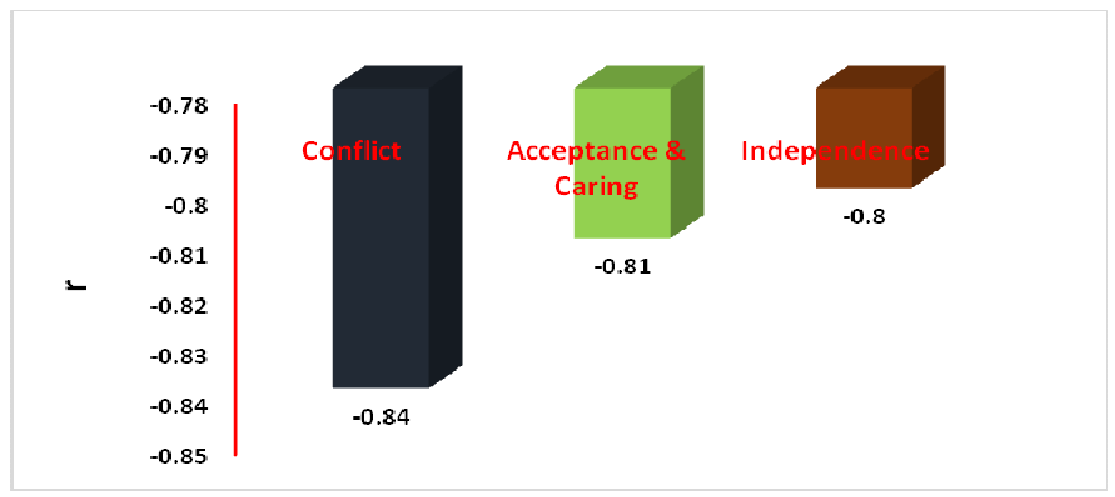

Figure 2. Correlation between Depression and Family environment of Female adults

Table $1 \& 2$ and Figure $1 \& 2$ revealed that depression and family environment among adults are negatively correlated irrespective of their gender. It indicates that the adults having poor family environment are more depressed whereas the adults having good family environment are less depressed.

\section{Conclusion}

It is concluded from the results of the present study that the depression among adults is significantly correlated with all the three dimensions of family environment irrespective to their gender.

\section{References}

Akram, B. \&Khuwaja, F. 2014. A study on depression among working and nonworking women of Gujrat, Pakistan. European Academic Research, 1(10), 2948-2962.

Beck, A.T., Steer, R.A. and Brown, G. K. 1996. Manual for the Beck Depression Inventory-II. The Psychological Corporation San Antonio. 7-14

Bhatia, H. \& Chadha, N.K. 2015. Manual for Family Environment Scale National Psychological Corporation, Agra. 5-8

Cairney, J, Boyle, M., Offord, D., and Racine, Y. 2003. Stress, social support, and depression in single and married mothers. Sociological Psychiatry and Psychiatric Epidemiology, 38: 442-449.

Carter, K.E., \& Seifert, C.M. 2016. Learn Psychology Jones \& Bartlett Publishers. 357.

Taylor, S. E., Way, B. M., Welch, W. T., Hilmert, C.J., Lehman, B. J., \& Eisenberger , N. I. 2006. Early Family Environment, Current Adversity, the Serotonin Transporter Promoter Polymorphism, and Depressive Symptomatology. Bio PsychiatryVol 60 (7):671-676.

Seligman, M. 1990. Learned Optimism: How to Change Your Mind and Your Life, New York: Pocket Books

Conflict of Interest: None declared 